\title{
INSTRUMENTO PEDAGÓGICO PARA AUXILIAR O TRABALHO DO EDUCADOR AMBIENTAL
}

\author{
Ari Silva Gobira ${ }^{1}$ \\ Áurea Regina Guimarães Tomasi²
}

Resumo: $O$ artigo é referente à elaboração de um produto técnico em atendimento às exigências do Programa de Mestrado Profissional do Centro Universitário Una. Portanto, este texto busca apresentar um relato da pesquisa de dissertação de mestrado com os ex-alunos de um projeto de formação de agentes ambientais. $O$ trabalho inclui ainda algumas considerações sobre inovação social, além de sugestões e informações que os entrevistados julgaram ser de interesse para auxiliar no trabalho socioambiental. Assim, este produto técnico é destinado a todos os educadores que sintam necessidade de um instrumento pedagógico para consultar ações ambientais e colaborar para o trabalho de conscientização, sensibilização e reflexão sobre a temática meio ambiente.

Palavras-chave: Meio Ambiente; Inovação Social; Caderno do Educador Ambiental; Produto Técnico. 


\section{Introdução}

O presente artigo busca apresentar o produto técnico elaborado em atendimento às exigências do Programa de Pós-Graduação em Gestão Social, Educação e Desenvolvimento Local, do Centro Universitário Una, proveniente da pesquisa de mestrado intitulada "Projeto Sala Verde: desdobramentos de uma educação para o meio ambiente e o desenvolvimento local". O Projeto Sala Verde é uma iniciativa do Departamento de Educação Ambiental do Ministério do Meio Ambiente (DEA/MMA), que busca incentivar a criação de espaços socioambientais para promover a distribuição e democratização das informações ambientais, por meio de projetos, ações e programas educacionais voltados para a questão ambiental3.

A dissertação que gerou esse produto técnico buscou analisar um dos espaços de formação ambiental, intitulado $\mathrm{BH}$ Itinerante, promovido pelo Projeto Sala Verde da Secretaria Municipal de Meio Ambiente (SMMA) da Prefeitura de Belo Horizonte/MG, localizado na Avenida Álvares Cabral, oㅡ 217, $14^{\circ}$ andar. O projeto conta ainda com outras atividades (oficina, travessia, visita orientada, ambiente em foco4), que são oferecidas gratuitamente a todos os cidadãos interessados. As atividades são realizadas entre os meses de março e junho e de agosto a novembro e podem ser consultadas no site 5 da Prefeitura de Belo Horizonte.

A ideia do curso BH Itinerante surgiu em 2000 após o curso "Intercâmbio em Educação Ambiental", que era ofertado exclusivamente para professores. Ao longo desse curso para docentes, percebeu-se a necessidade de ampliar o público de modo que todos os cidadãos, independentemente da sua formação acadêmica e ocupação, também pudessem frequentá-lo. Desse modo, criou-se o $\mathrm{BH}$ Itinerante, que passou a fazer parte das atividades do Projeto Sala Verde - Centro de Extensão em Educação Ambiental, oferecidas pela SMMA (BELO HORIZONTE, 2016). Tem duração de, aproximadamente, cinco meses, sendo realizados 18 encontros semanais, com aula teórica e prática, totalizando 120 horas/aula (BELO HORIZONTE, 2005; 2016).

A pesquisa contou com uma amostra de 26 agentes ambientais do projeto, que participaram de uma entrevista semiestruturada. $O$ objetivo principal da pesquisa foi analisar de que maneira as práticas de Educação Ambiental (EA) do projeto estavam sendo implementadas pelos egressos em seu local de origem.

\footnotetext{
${ }^{3}$ http://www.mma.gov.br/educacao-ambiental/educomunicacao/salas-verdes\#oprojeto.

${ }^{4}$ As oficinas são cursos de três horas de duração que promovem reflexão e debate em torno das temáticas ambientais. As travessias e visitas orientadas são atividades de campo com duração de quatro horas/aula, que permitem aos participantes vivenciar trabalhos e projetos socioambientais na região metropolitana de Belo Horizonte. Já o ambiente em foco oferece sessões comentadas de documentários e curtas-metragens em torno da questão socioambiental (BELO HORIZONTE, 2005).

${ }^{5}$ http://portalpbh.pbh.gov.br/pbh/ecp/comunidade.do?evento=portlet\&pldPIc=ecpTaxonomiaMen uPortal\&app=meioambiente\&tax $=24081 \&$ lang=pt_br \&pg $=5700 \& \operatorname{taxp}=0 \&$.
}

Revbea, São Paulo, V. 12, № 1: 123-138, 2017. 
Logo, por se tratar de uma pesquisa voltada para a temática de EA, buscou-se construir um produto técnico que atendesse aos objetivos $\mathrm{e}$ recomendações da Política Nacional de Educação Ambiental (PNEA) (Lei no 9.795/99), permitindo a participação e democratização das informações ambientais (BRASIL, 1999). Dessa forma, o produto técnico não seria algo imposto e idealizado somente na visão dos pesquisadores, mas algo que fosse elaborado a partir da sugestão dos interessados em construir um produto que representasse as necessidades e as dificuldades desses colaboradores.

Nessas condições, buscou-se adotar alguns dos pressupostos da inovação social ao longo do levantamento de dados, assim como do processo de sondagem das contribuições dos colaboradores. Isso porque a inovação social é entendida como uma resposta às "necessidades sociais", pressupondo a "participação" e "cooperação" de todos os sujeitos envolvidos e gerando novas soluções para os grupos sociais, comunidades ou para a sociedade em geral (BIGNETTI, 2011, p.4).

Assim, todos os egressos interessados em participar da construção do produto técnico puderam dar suas contribuições para a estruturação do caderno do educador ambiental, com recomendações de livros, filmes, atividades lúdicas, entre outros recursos, para auxiliar no trabalho da temática ambiental. Sem dúvida, a colaboração dos egressos do projeto de formação que foram entrevistados na pesquisa e de terceiros 6 foi de grande importância para a construção desse produto técnico que reuniu a ideia inicial dos pesquisadores e agregou novas ideias que vieram colaborar com os educadores ambientais.

\section{Discussão teórica}

A proposta da EA brasileira é regulamentada por meio da Política Nacional de Educação Ambiental (PNEA) (Lei no 9.795/99) e do Decreto no 4.281/2002, que regulamentou a lei e criou o órgão gestor, sendo coordenado pelos Ministérios do Meio Ambiente e da Educação (BRASIL, 2014). A EA pode ser entendida como um processo de aprendizagem longo e contínuo, sempre levando em consideração os valores culturais, sociais e políticos, mas sempre tendo a transmissão de conhecimentos a partir das discussões e avaliações que permitam aos participantes refletir de forma crítica e participativa a sua realidade individual e social, na sociedade em que vivem (GONÇALVES, 1990).

É evidente que a EA não se trata de um trabalho novo na sociedade, tendo sua fundamentação a partir do momento em que a degradação ambiental passa a ser um grande desconforto para a sociedade diante do latente crescimento industrial (ALBANUS; ZOUVI, 2013). A partir desse momento,

6 São todos aqueles colaboradores que não fizeram parte do público-alvo da pesquisa, representado por gestores do projeto, educadores ambientais e bibliotecários, que aceitaram participar da construção do Caderno do Educador Ambiental.

revista brasileira educação ambiental 
vários encontros organizados por especialistas e representantes dos países membros da Organização das Nações Unidas (ONU) propiciaram para que a EA fosse efetivada. Um desses encontros foi o Congresso de Tbilissi (1977), por ter definido os objetivos, as características e estratégias para 0 desenvolvimento das atividades de EA.

No entanto, trabalhar com esse eixo temático não é algo simples, uma vez que a temática ambiental faz parte de um campo diverso, complexo e plural, marcado pela ação de diferentes atores e setores sociais, que influenciaram direta e indiretamente os seus caminhos (TRISTÃO; TRISTÃO, 2016). De fato, vivemos numa sociedade que se encontra em constante transformação, seja pela interferência dos fatores locais ou globais, que acabam influenciando o funcionamento e o posicionamento da sociedade para as relações socioambientais. Acrescente-se a isso a rapidez com que as informações são disponibilizadas para a sociedade e que estas, de alguma forma, interferem no trabalho e na reflexão da temática em questão, fazendo com que a EA seja considerada um processo em permanente construção, conforme afirmam Vasconcellos et al. (2009).

Nesses casos, é preciso constantemente buscar informações e inovar a forma de trabalhar os conteúdos ambientais, já que aspectos como linguagem, abordagem e articulação dos diversos conhecimentos acabam influenciando na condução e planejamento das ações de EA, exigindo do educador habilidades para saber adequar os conteúdos ao contexto social, ambiental, político, econômico, ético e cultural (BRASIL, 2014).

Essa situação leva ainda a uma outra exigência da EA, a participação social, que é fundamental para o eixo norteador das práticas de EA, exigindo articulação de saberes e fazeres dos envolvidos, para resolver as complexas questões socioambientais. Para isso, sempre busca a reflexão e engajamento para uma proposta pedagógica centrada na criticidade e na emancipação desses sujeitos, tendo em vista a mudança de comportamento e atitudes focadas no desenvolvimento da organização social e da participação coletiva (JACOBI; TRISTÃO; FRANCO, 2009).

A partir dessa visão, pode-se supor que o sentido da inovação social pode ser um aliado para a construção de estratégias que colaborem com os princípios e objetivos previstos na PNEA. O conceito da inovação social atribuído por Bignetti $(2011$, p. 3) é "[...] o resultado do conhecimento aplicado a necessidades sociais através da participação e da cooperação de todos os atores envolvidos, gerando soluções novas e duradouras para grupos sociais, comunidades ou para a sociedade em geral'.

A inovação social não visa a um ideal tecnológico, apesar de ser comum associar o seu sentido ao da inovação tecnológica, mas tem caráter coletivo e transformador, que colabora para as transformações das relações sociais (ANDRÉ; ABREU, 2006). Para Barboza Lacerda e Vieira Ferrarini (2013), compreende-se a inovação social como uma ação que parte da participação popular, tendo seus membros como os principais agentes da 
transformação e atuação e ainda que toda e qualquer produção originada desse movimento seja de usufruto de todos, sem qualquer privação dos direitos e favorecimento desigual.

Isso leva a se considerar que, para a EA ter desdobramentos e se tornar de fato efetiva, promovendo mudanças nas concepções e atitudes dos indivíduos e da sociedade como um todo, para conservação e manutenção do meio ambiente, é preciso ser inovadora e, portanto, seguir os pressupostos da inovação social.

Conforme afirma Vasconcellos et al. (2009, p. 32), "[...] a EA é uma educação política que se apoia em uma visão de mundo complexa e, por isso, é muito mais do que sensibilização, embora também a envolva", ou seja, trabalhar com a Educação Ambiental não é simplesmente buscar a sensibilização, mas buscar trabalhar uma "[...] atitude de ação-reflexão-ação em torno da problemática ambiental" (JACOBI; TRISTÃO; FRANCO, 2009, p. $66)$.

Observa-se que, da mesma forma que a inovação social visa à transformação social, a Educação Ambiental busca trabalhar esse ideal transformador a fim de promover mudanças no comportamento dos indivíduos, tendo como proposta uma prática dialógica que busque trabalhar numa perspectiva crítica por parte da sociedade e que esteja comprometida com a problemática ambiental, percebendo a inter-relação dos aspectos sociais, ecológicos, econômicos, políticos, culturais, científicos, tecnológicos e éticos (TRISTÃO; TRISTÃO, 2016).

No que concerne à educação, "destaca-se, igualmente, que a inovação não é um fim em si mesma, mas um meio para transformar os sistemas educacionais" (MESSINA, 2001, p. 226). Partindo desse princípio, essa mesma autora completa dizendo que a inovação social pode ser definida como um processo multidimensional, responsável pela transformação do espaço no qual habita e de si própria, em uma disposição permanente em direção à inovação ou de inovar a própria inovação.

Para Carbonell (2002), a inovação na educação não está associada às reformas da estrutura educacional, mas sim na renovação pedagógica das escolas. O simples fato de modernizar o espaço escolar não se caracteriza como um processo inovador, da mesma forma que simplesmente promover saídas de campo ou idealizar o cultivo de hortas e oficinas não significa uma inovação e uma mudança na prática ambiental (CARBONELL, 2002).

Geralmente, os processos denominados de "inovação" no espaço escolar são algo imposto pelo sistema educacional, que são idealizados numa concepção que não leva em consideração a realidade e a diversidade geográfica das escolas, construindo propostas generalizadas a serem seguidas e aplicadas. Messina (2001) diz que quando o processo acontece de forma imposta, pode gerar resistência e dificuldade para que a proposta seja aceita pelos envolvidos. A inovação precisa ser construída de forma conjunta com os sujeitos envolvidos, da mesma forma que a concepção de EA, sempre levando

revista brasileira educação ambiental 
em consideração a participação e o respeito à pluralidade e à diversidade étnica, racial, social e cultural, seja ela individual ou coletiva (BRASIL, 2014).

Assim, neste debate para se analisar se determinada prática pode ser considerada uma inovação social, podem-se considerar alguns pressupostos com base em Andrade (2005), Bignetti (2011), Camarotti (2004), Spink (2003), Carbonell (2002) e Morin (2010), conforme a lista que se segue:
a) Articular os saberes, não fracionar ou fragmentar o conhecimento;
b) pensar na complexidade;
c) construir novos ambientes;
d) considerar fatores econômicos, políticos, sociais, mas também culturais;
e) contextualizar;
f) contemplar a interdisciplinaridade;
g) fazer sentido, ter um significado para as pessoas envolvidas;
h) descentralizar decisões e ações;
i) democratizar a informação;
j) incorporar e transformar a realidade;
k) envolver o entorno;
l) promover mudança no cotidiano;
m) estabelecer uma relação entre o todo e as partes;
n) relacionar local e global;
o) focar na resolução de problemas sociais;
p) mobilizar pessoas e recursos em torno de objetivos comuns;
q) buscar parcerias, alianças e serviços para solução de problemas sociais;
r) atuar na perspectiva da intersetorialidade;
s) promover a participação e a cogestão/ gestão integrada.

Pode-se perceber, a partir dessa listagem, que esses pressupostos podem colaborar para uma proposta de EA transformadora, que busque se articular com a mudança social, por meio de uma proposta educativa que trabalhe com a cooperação entre educadores e demais sujeitos engajados nas lutas sociais e ambientais. E que permita a criação de espaços críticos de aprendizagem que extrapolem os limites da educação formal (JACOBI; TRISTÃO; FRANCO, 2009). Dito de outra forma, a EA deve permitir a participação e o envolvimento de toda a comunidade do entorno, por meio de ações que articulem os saberes e levem em consideração os fatores econômicos, políticos, sociais e culturais. $\mathrm{E}$, ao mesmo tempo, que vença as próprias limitações no que diz respeito às práticas interdisciplinares e intersetoriais, tão fundamental para um trabalho que valorize e integre diferentes áreas do conhecimento e instituições colaboradoras.

Para concluir essa relação da inovação social com a prática de EA, toma-se uma citação de Franco (2006), que exemplifica uma busca inovadora para desenvolver uma práxis pedagógica, no sentido de potencializar pensamento e ação reflexiva desses sujeitos-agentes do ensino e 
aprendizagem. Essa práxis os prepara para a transformação da realidade por meio do conhecimento escolar, desenvolvido em diferentes contextos sociais e materiais.

A Educação Ambiental e seus referenciais teóricometodológicos têm se configurado em importante eixo capaz de construir e concretizar, em espaços formais e informais da educação, uma prática pedagógica instrumentalizadora para uma nova era. Os saberes desvinculados da realidade não têm mais razão de ser, tampouco uma visão maniqueísta de mundo, 0 isolamento das disciplinas, a ditadura do racionalismo, as dicotomias que separam alma e corpo, razão e emoção, teoria e prática. A Educação Ambiental busca uma educação para um ser humano integral, que assuma a complexidade, a globalidade, a criticidade e a responsabilidade pelo destino comum da humanidade sem desrespeitar as identidades culturais e a diversidade das múltiplas sociedades que fazem parte do planeta (FRANCO, 2006, p. 9).

\section{Produto técnico: o caderno do educador ambiental}

Portanto, partindo dos pressupostos que determinam se uma prática pode ser considerada uma inovação social, buscou-se levantar com os sujeitos da pesquisa um produto técnico que atendesse às exigências do Programa de Mestrado em Gestão Social, Educação e Desenvolvimento Local, do Centro Universitário Una. E que esse produto não fosse imposto pelos pesquisadores aos participantes da pesquisa e, ainda, que representasse as necessidades dos egressos do curso de formação ambiental, para promover e viabilizar as ações desses agentes ambientais.

Dessa forma, ao final das entrevistas tentou-se explicar aos participantes a exigência do produto técnico e indagar sobre que tipo de recurso deveria ser inserido que, ao mesmo tempo, colaborasse com as práticas dos cursistas do projeto. Assim, cada participante pôde apresentar inicialmente suas sugestões e opiniões, que eram, então, expostas posteriormente aos próximos participantes sem qualquer identificação dos mesmos. Assim, eram apresentadas as ponderações positivas e negativas sobre a ideia do produto técnico, sempre trazendo o amadurecimento da ideia inicial para o próximo entrevistado. Essa estratégia teve que ser adotada, uma vez que a pesquisa deve zelar pelo anonimato dos participantes.

No geral, a estratégia adotada possibilitou a participação, a articulação e as sugestões, colaborando para o levantamento de dados que resultaram na organização do caderno do educador ambiental - produto técnico desta pesquisa.

A partir desse levantamento preliminar, definiram-se quais seriam os recursos que deveriam constar no produto técnico, sendo acordado que o 
caderno do educador deveria trazer sugestão de vídeos, sites, documentários, livros e atividades lúdicas. Portanto, para que pudessem levantar o conteúdo de cada um desses recursos, foi encaminhado um formulário a alguns participantes que manifestaram interesse em participar da construção do produto técnico, para que pudessem apresentar sugestões/dicas que considerassem interessantes e importantes de serem compartilhadas entre os colegas.

Esses recursos pedagógicos foram sugeridos pelos agentes ambientais do projeto. Vale ressaltar que o intuito foi a construção de uma produção que trouxesse não só conteúdo teórico sobre as temáticas ambientais, mas sugestões de recursos e ações que pudessem colaborar com o trabalho da EA por meio de atividades lúdicas, da literatura e de recursos visuais, além de idealizar algo que trouxesse características de inovação social e colaborasse para o desenvolvimento local.

Porém, a necessidade de trabalhar a questão dos projetos socioambientais foi evidenciada após as análises dos dados da pesquisa, mostrando que alguns egressos têm dificuldades na idealização e implementação de projetos de EA. Logo, procurou-se trazer um item específico para a construção de projetos, diante das reais necessidades dos egressos e da pesquisa, reunindo todas essas necessidades num único produto técnico.

\section{Ferramentas pedagógicas para auxiliar no trabalho da Educação Ambiental}

Finalizada essa etapa de levantamentos das sugestões, os dados foram organizados e verificados, de modo a identificar a procedência das informações e recomendações.

Nessas condições, para melhor apresentação das informações no Caderno do Educador Ambiental, buscou-se agrupar as indicações pelo critério de semelhança, dividindo-o em quatro categorias: recursos digitais, recursos impressos, recursos lúdicos e recursos visuais. Todas as informações recebidas foram analisadas previamente e posteriormente organizadas para apresentação aos futuros interessados nessa produção técnica, já que a maior parte das informações não possuía identificação de autoria.

No caso dos recursos visuais e impressos, foi criada uma ficha técnica para fornecer informações sobre o conteúdo, trazendo autoria, editora e sinopse. As sugestões de recursos lúdicos não foram apresentadas juntamente com os recursos impressos. Já estes tiveram outro agrupamento, mas adotouse o mesmo critério anterior para referenciar as sugestões. Além disso, para as obras que não tinham informações sobre autoria e/ou produção, foi informado o link de acesso, como segunda forma de dar crédito aos autores ou instituições que estão disponibilizando a informação.

Já os recursos digitais, os sites, foram todos organizados por temática, de modo a facilitar a consulta do educador. Salienta-se que os sites acabam Revbea, São Paulo, V. 12, № 1: 123-138, 2017. 
trazendo informações sobre mais de uma temática ou acesso a outras informações ambientais que eventualmente possam ser de interesse de algum educador ambiental (Quadro 1).

Quadro 1: Organização das informações coletadas dos egressos do BH Itinerante

\begin{tabular}{|c|c|c|}
\hline DESCRIÇÃO & CONTEÚDO & APRESENTAÇÃO \\
\hline $\begin{array}{c}\text { RECURSOS } \\
\text { DIGITAIS }\end{array}$ & $\begin{array}{l}\text { São apresentadas as relações de } \\
\text { sites institucionais, de empresas e } \\
\text { órgãos públicos. }\end{array}$ & $\begin{array}{l}\text { As informações foram organizadas por } \\
\text { temática, de modo a facilitar a consulta do } \\
\text { educador ambiental. }\end{array}$ \\
\hline $\begin{array}{l}\text { RECURSOS } \\
\text { IMPRESSOS }\end{array}$ & $\begin{array}{l}\text { São apresentados cadernos, } \\
\text { guias, manuais e livros. Algumas } \\
\text { produções estão disponíveis para } \\
\text { o educador fazer download. Neste } \\
\text { caso, é informado o link de acesso } \\
\text { à produção. }\end{array}$ & $\begin{array}{l}\text { Todas as informações foram organizadas } \\
\text { por ordem alfabética, colocando o título, } \\
\text { autor, editora e sinopse. Esta regra foi } \\
\text { adotada sempre que possível, já que nem } \\
\text { sempre a informação encontra-se } \\
\text { disponível na produção indicada. Para } \\
\text { estes casos, manteve-se a sugestão e foi } \\
\text { inserido o site para acesso, a fim de } \\
\text { referenciar a sugestão. }\end{array}$ \\
\hline $\begin{array}{c}\text { RECURSOS } \\
\text { LÚDICOS }\end{array}$ & $\begin{array}{l}\text { No item recursos lúdicos, são } \\
\text { listados alguns livros que trazem } \\
\text { atividades lúdicas, além de alguns } \\
\text { sites que sugerem atividades, } \\
\text { jogos e ações práticas. }\end{array}$ & $\begin{array}{l}\text { Em virtude de ser um item do Caderno do } \\
\text { Educador, os livros que trazem atividades } \\
\text { lúdicas foram listados na categoria } \\
\text { recursos impressos. Algumas sugestões } \\
\text { estão disponíveis para download, assim } \\
\text { foi informado o link de acesso ao final da } \\
\text { descrição da atividade. }\end{array}$ \\
\hline $\begin{array}{c}\text { RECURSOS } \\
\text { VISUAIS }\end{array}$ & $\begin{array}{l}\text { Nesta última categoria, foram } \\
\text { listados documentários e vídeos, } \\
\text { sugeridos pelos egressos do } \\
\text { projeto de formação. }\end{array}$ & $\begin{array}{l}\text { Usaram-se os mesmos critérios de } \\
\text { organização dos recursos impressos. } \\
\text { Nesta categoria também existiu a } \\
\text { dificuldade de localizar algumas } \\
\text { informações, principalmente os vídeos. } \\
\text { Assim, para este item específico, há } \\
\text { somente o link de acesso da sugestão. }\end{array}$ \\
\hline
\end{tabular}

\section{Elaboração de projetos de Educação Ambiental}

A ideia de fomentar programas, projetos e ações de Educação Ambiental é um dos objetivos estabelecidos pelo Programa Nacional de Educação Ambiental (ProNEA), (BRASIL, 2014), entendendo que estes podem colaborar para difundir a legislação ambiental (BRASIL, 2014). O ProNEA traz ainda entre suas linhas de ação e estratégias ações que busquem estimular e apoiar a criação de programas de Educação Ambiental e sua inclusão nos projetos públicos e privados que causem impactos ambientais (BRASIL, 2014).

Segundo Barbosa (2001), a definição de projeto pode ser algo amplo, por ser aplicado a qualquer modelo de planejamento, mas quando comparado a planos e programas, normalmente são caraterizados por serem mais limitados nos aspectos relacionados ao tempo, espaço e recursos. Os projetos 
têm a sua origem a partir de sugestões dos sujeitos envolvidos, gestores, beneficiários, para sanar problemas, pois estes traduzem com mais propriedade a realidade e as necessidades dos envolvidos, favorecendo 0 melhor alcance, aproveitamento e conhecimento de cada sujeito (BARBOSA, 2001).

Assim, a construção de projeto está sempre associada a algo que se transforma no presente e se deseja alcançar no futuro, por meio da construção de novos cenários, tendo no mínimo dois componentes distintos, mas interligados, o que se quer atingir e como se vai atingir (ROSA, 2007). No entanto, a construção de projeto de Educação Ambiental, nem sempre é algo simples de ser estruturado, conforme ficou evidenciado durante a pesquisa com os egressos do projeto $\mathrm{BH}$ Itinerante, já que algumas pessoas não sabem como iniciar e/ou executar as ações de maneira a que se tenha a participação e colaboração dos sujeitos envolvidos.

Portanto, duas referências podem auxiliar os interessados na estruturação de projeto socioambientais. A primeira sugestão, texto: "Onze passos do planejamento estratégico participativo", elaborado por Marcos José Pereira Silva, organizado numa concepção de estratégia participativa, conforme afirma o autor. Este texto faz parte do livro "Metodologia Participativa - uma introdução a 29 instrumentos", que foi organizado por Markus Brose. O texto traz orientações que auxiliam no planejamento participativo para enfrentar de modo eficiente e eficaz um conflito, tomando como base os métodos Planejamento Estratégico Situacional (PES) e Método Altadir de Planejamento Popular (MAPP), ambos criados pelo chileno Carlos Matus (SILVA, 2010).

A segunda sugestão é um roteiro para elaboração de projetos de Educação Ambiental, elaborado pela Coordenadoria de Educação Ambiental da Secretaria do Meio Ambiente do Estado de São Paulo. Esse roteiro traz o passo a passo para estruturação de um projeto, apresentando os detalhes necessários que devem ser considerados durante a idealização do planejamento, que podem auxiliar municípios, escolas ou instituições da sociedade civil (SÃO PAULO, 2013).

Durante a execução de projetos socioambientais, recomenda-se que o propositor desenvolva avaliações para acompanhamento das ações que são propostas ao longo do planejamento. No entanto, a prática de avaliação em projetos é bastante debatida e sua aplicação não é usualmente utilizada pelos gestores dos projetos, sendo limitada ao controle de investimentos financeiros ou simplesmente com relatório das ações desenvolvidas (ASSUMPÇÃO; CAMPOS, 2011).

Conforme Assumpção e Campos (2011), a avaliação de um projeto pode ser realizada em três momentos distintos, sendo eles: antes (ex-ante) de realizar as ações previstas pelo projeto; durante (in-itineri) a execução do mesmo; e depois (ex-post) do projeto aplicado. Quando se realiza a avaliação ex-ante, é possível levantar informação prévia sobre a realidade do local onde as intervenções do projeto acontecerão, além de permitir a escolha das 
estratégias para conseguir o atendimento dos objetivos do projeto. Durante a execução do projeto, momento in-itineri, desenvolvem-se avaliações e monitoramentos para verificação das ações em andamento, sendo possível identificar se as intervenções estão sendo suficientes e até mesmo identificar possíveis ajustes das ações. Já o ex-post possibilita aos gestores avaliarem os impactos das intervenções e permite tomada de decisões referentes à continuidade e eventuais alterações do projeto.

Existem diversos modelos teóricos de avaliação que podem ser aplicados conforme as habilidades práticas do avaliador, vínculos e interesses dos gestores (ASSUMPÇÃO; CAMPOS, 2011). O uso de questionários, entrevistas, roda de conversa, autoavaliações e indício de mudança de hábitos são alguns dos métodos que podem ser utilizados para a avaliação (SÃO PAULO, 2011). Durante a avaliação é interessante contemplar formas participativas de avaliação, de maneira que inclua todos os envolvidos direta e indiretamente com o projeto e, inclusive, os beneficiários (SÃO PAULO, 2013).

Assim, algumas referências bibliográficas podem auxiliar aos interessados no aprofundamento sobre a avaliação de projetos e indicadores. Vejam-se:

- Avaliação para o investimento social privado: metodologias. Organização: Fundação Itaú Social, Fundação Roberto Marinho, Fundação Maria Cecília Souto Vidigal, Move.

- BORBA, Paulo da Rocha Ferreira et al. Monitoramento e avaliação de programas e projetos sociais: desenvolvimento de um plano de avaliação. 2004.

- BUVINICH, Manuel Rojas. Ferramentas para o monitoramento e avaliação de programas e projetos sociais. 1999.

- CEPAL/Division de Desarrollo Social. Manual de formulação e avaliação de projetos sociais. 1997.

No que concerne ao projeto como um todo, o propositor deverá tomar alguns pontos sugeridos por Buvinich (1999), CEPAL (1997), Almeida (2006), Cabral (2011) e Assumpção e Campos (2011), durante a construção do planejamento, como:

a) Idealização social: pressupõe que um projeto deve ter a participação e o acompanhamento dos sujeitos em sua idealização e implementação;

b) definições: deve-se definir quem serão os beneficiários, diretos e indiretos, e possíveis opositores ao projeto, pois esses sujeitos devem estar explícitos para permitir traçar as estratégias e ações;

c) envolvimento: um projeto deve possuir envolvimento de pessoas, grupos ou comunidades e colaboradores (direto e indireto) do projeto social; 
d) transformação: o projeto deve visar à transformação da realidade para o bem comum, promovendo 0 desenvolvimento local. $E$ essa transformação deve acontecer sem fins lucrativos;

e) eficácia: refere-se à capacidade administrativa do projeto para atender às metas ou aos resultados propostos;

f) eficiência: busca-se produzir o máximo de resultados com o mínimo recurso e;

g) efetividade: deve-se verificar a relação entre os custos e objetivos do projeto.

Dessa forma, quando o propositor segue essas recomendações, possibilita uma proposta de Educação Ambiental transformadora e participativa, já que terá o envolvimento e a contribuição de todos os interessados durante 0 planejamento, execução e avaliação do projeto.

\section{Conclusões}

A experiência de construir esse produto técnico foi de grande importância para os autores. Entretanto, ressalta-se que todas essas propostas devem ser desenvolvidas seguindo-se os pressupostos de inovação social, uma vez que se reafirma a ideia de que nenhuma intervenção deve ser construída numa lógica de imposição, sem se levar em consideração a realidade e necessidade dos sujeitos. A própria elaboração desse Caderno do Educador Ambiental vai ao encontro do sentido da inovação social, já que foi construído levando-se em consideração a participação dos sujeitos envolvidos na pesquisa, visando a uma produção que pudesse colaborar e facilitar o trabalho desses educadores.

Durante toda a construção do caderno do educador foi possível escutar algumas das dificuldades da mobilização, descrita por Toro e Werneck (1996): o fato de lidar com pessoas e opiniões. Essa dificuldade foi muitas vezes relatada pelos participantes da pesquisa, demonstrada no trato com os sujeitos envolvidos nos processos de sensibilização e conscientização, além da dificuldade de motivá-los a participar e idealizar projetos socioambientais.

Assim, com a elaboração deste produto técnico, espera-se que algumas dificuldades possam ser minimizadas, por meio da orientação de como construir um projeto socioambiental, tendo como foco os princípios da inovação e a mobilização social. No que se refere às dificuldades com recursos pedagógicos, acredita-se que as informações coletadas possam ajudar, ainda que diante da quantidade de informações disponíveis na internet, as colaborações possam ser consideradas insignificantes. De qualquer forma, os educadores podem buscar outras e até mesmo novas informações por meio da internet.

Para concluir, apresenta-se o link de acesso à versão digital do produto técnico https://1drv.ms/t/s!AgVYtig6wdiAkFvN6iWmIL91WnsX, que pode ser 
coleta de sugestões dos egressos do $\mathrm{BH}$ Itinerante, adotou-se o recebimento de colaboração de outros sujeitos que aceitaram participar e indicar produções para o caderno do educador. Com o intuito de continuar recebendo novas sugestões, o manual traz orientação para os interessados sobre como colaborar com informações e submetê-las aos organizadores do produto técnico. Pretende-se, portanto, que este caderno em sua versão on-line seja constantemente atualizado e enriquecido.

\section{Referências}

ALBANUS, L.L.F.; ZOUVI, C.L. Ecopedagogia: educação e meio ambiente. Curitiba: Intersaberes, 2013 (Série Pedagogia Contemporânea).

ALMEIDA, V.P. Avaliação de programas sociais: de mensuração de resultados para uma abordagem construtivista. Pesquisas e Práticas Psicossociais, São João del-Rei, v. 1, n. 2, dez. 2006. Disponível em: $<$ http://www.ufsj.edu.br/portal-repositorio/File/revistalapip/VicenteAlmeida.pdf>. Acesso em: 14 abr. 2016.

ANDRADE, T. Inovação e Ciências Sociais em busca de novos referenciais. RBCS, v. 20, n. 58, jun. 2005.

ANDRÉ, I.; ABREU, A. Dimensões e espaços da inovação social. Finisterra, v. $\mathrm{XLI}$, n. 81, p. 121-141, 2006. Disponível em: <http://revistas.rcaap.pt/ finisterra/article/view/1465/1160>. Acesso em: 05 dez. 2016.

ASSUMPÇÃO, J.J.; CAMPOS, L.M.S. Avaliação de projetos sociais em ONGs da Grande Florianópolis: um estudo sobre modelos relacionados ao foco de atuação. Rev Adm Pública [online]. v. 45, n. 1, pp. 209-242, 2011. ISSN 00347612. Disponível em: <http://dx.doi.org/10.1590/S0034-76122011000100010>. Acesso em: 4 fev. 2013.

BARBOSA. R. Monitoramento e avaliação de projetos sociais. Trabalho de conclusão (Especialização em Desenvolvimento Rural e Agroecologia) Universidade Federal do Rio Grande do Sul, Porto Alegre, 2001.

BARBOZA LACERDA, L.F.; VIEIRA FERRARINI, A. Inovação social ou compensação?: reflexões acerca das práticas corporativas. Polis, Santiago, v. 12, n. 35, p. 357-379, ago. 2013. Disponível em: $<$ http://www.scielo.cl/scielo.php?script=sci arttext\&pid=S071865682013000200016\&lng=es\&nrm=iso $>$. Acesso em: 05 dez. 2016.

BELO HORIZONTE. Prefeitura. Secretaria Municipal de Meio Ambiente. Projeto Sala Verde: Centro de Extensão em Educação Ambiental. Belo Horizonte/MG, abr. 2005. 
BELO HORIZONTE. Prefeitura. Secretaria Municipal Adjunta de Meio Ambiente. Relatório Final do XXXI BH Itinerante: curso de extensão em Educação Ambiental. Projeto Sala Verde - Centro de Extensão em Educação Ambiental. Belo Horizonte/MG, jan. 2016.

BIGNETTI, L.P. As inovações sociais: uma incursão por ideias, tendências e focos de pesquisa. Ciências Sociais Unisinos, v. 47, n. 1, p. 3-14, jan.-abr. 2011. Disponível em: <http://revistas.unisinos.br/index.php/ciencias sociais/article/view/1040/235>. Acesso em: 05 nov. 2016.

BORBA, P.R.Ferreira et al. Monitoramento e avaliação de programas e projetos sociais: desenvolvimento de um plano de avaliação. VI SEMEAD, Anais..., São Paulo, 2004. Disponível em: $<$ http://teleduc.unisa.br/ teleduc/cursos/diretorio/apoio

5504 227/TS03 Monitoramento e Avaliao de Proj Sociais06062012.pdf>. Acesso em: 05 jan. 2017.

BRASIL. Ministério do Meio Ambiente e Ministério da Educação. Programa Nacional de Educação Ambiental. Brasília: MMA e MEC, 4. ed., 2014. 112 p.

BRASIL. Ministério do Meio Ambiente. Lei no 9.795, de 27 de abril de 1999. Disponível em: <http://www.planalto.gov.br/ccivil 03/decreto/2002/d4281.htm> Acesso em: 22 nov. 2015.

BRASIL. Ministério do Meio Ambiente. Ministério da Educação. Programa Nacional de Educação Ambiental. Brasília: MMA e MEC, 4. ed., 2014. 112 p.

BUVINICH, Manuel Rojas. Ferramentas para o monitoramento e avaliação de programas e projetos sociais. Cadernos de Políticas Sociais. Série Documentos para Discussão ํo 10. Unicef. 1999. Disponível em: $<$ http://pt.slideshare.net/brunommss/buvinich-manuel-rojas-ferramentas-paraavaliacao-monitoramento-de-programas-projetos-sociais>. Acesso em: 28 abr. 2016.

CABRAL, E.H.S. Valores e espaço público: referenciais e instrumentos para a avaliação de projetos sociais. RAP, Rio de Janeiro, v. 45, n. 6, p. 1915-41, nov./dez. 2011. Disponível em: <http://www.anpad.org.br/admin/pdf/apb962.pdf http://unesav.com.br/ckfinder/userfiles/files/MANUAL DE FORMULACAO E AVALIACAO DE PROJETOS SOCIAIS.pdf>. Acesso em: 14 abr. 2016.

CAMAROTTI, I. Construção de indicadores de desenvolvimento local. In: IX CONGRESO INTERNACIONAL DEL CLAD SOBRE LA REFORMA DEL ESTADO Y DE LA ADMINISTRACIÓN PÚBLICA, Madrid, España, p. 2-5, Anais..., Nov. 2004. Disponível em:<http://www.gp.usp.br/files/desen indicadores.pdf $>$. Acesso em: abr. de 2016. 
CARBONNEL, J. A aventura de inovar: a mudança na escola. (Trad. Fátima Murad), Porto Alegre: Artmed, 2002.

CEPAL/Division de Desarrollo Social. Manual de formulação e avaliação de projetos sociais. $1997 . \quad$ Disponível em: $<$ http://unesav.com.br/ckfinder/userfiles/files/MANUAL \%20DE\%20FORMULACAO\%20E\%20AVALIACAO\%20DE\%20PROJETOS\%2 0SOCIAIS.pdf $>$. Acesso em: 28 abr. 2016.

FRANCO, M.I. Agenda 21 na educação: construindo ferramentas pedagógicas para trilhar o caminho da sustentabilidade. Agenda 21 - Educação ambiental em áreas de proteção aos mananciais. São Paulo/Embu: Fundo Estadual de Recursos Hídricos, 2006, p. 8-18. Disponível em: $<$ http://seaembu.org/docs/ag21 mananciais.pdf >. Acesso em: 06 dez. 2016.

GONÇALVES, D.R.P. A Educação Ambiental e o ensino básico. In: IV SEMINÁRIO NACIONAL SOBRE UNIVERSIDADE E MEIO AMBIENTE. Florianópolis. UFSC, 1990. Textos básicos, p. 125-146, 1990.

JACOBI, P.R.; TRISTÃO, M.; FRANCO, M.I.G.C. A função social da Educação Ambiental nas práticas colaborativas: participação e engajamento. Cadernos Cedes, Campinas, v. 29, n. 77, p. 63-79, jan./abr. 2009.

MESSINA, G. Mudança e inovação educacional: notas para reflexão. Cad Pesqui, São Paulo, n. 114, p. 225-233, nov. 2001. Disponível em: $<$ http://www.scielo.br/scielo.php?script=sci arttext\&pid=S0100-

$15742001000300010 \& \mathrm{lng}=\mathrm{pt \& n}$ rm=iso $>$. Acesso em: $06 \mathrm{dez} .2016$.

MORIN, E.. Ciência com consciência. 9. ed., capítulo 6 - 1a. parte. Rio de Janeiro: Bertrand Brasil, 2005.

ROSA, A.V. Projetos em Educação Ambiental. In: FERRARO-JR, L.A. (Org.). Encontros e caminhos: formação de educadoras(es) ambientais e coletivo educadores. Brasília: MMA, Departamento de Educação Ambiental, 2007, p. 273-287.

SANTANA, O.; FONSECA, A. Ciências Naturais. 6ª série. 2. ed., São Paulo: Saraiva, 2006.

SÃO PAULO (Estado). Secretaria do Meio Ambiente. Coordenadoria de Educação Ambiental. Roteiro para elaboração de projetos de Educação Ambiental. Texto Caroline Vivian Gruber; Denise Scabin Pereira; Rachel Marmo Azzari Domenichelli. São Paulo: SMA/CEA, 2013. 40 p. Disponível em: $<$ http://www.ambiente.sp.gov.br/cea/files/2014/01/roteiro-proj-ea.pdf>. Acesso em: 06 dez. 2016. 
SÃO PAULO (Estado). Secretaria do Meio Ambiente. Coordenadoria de Educação Ambiental. Roteiro básico para elaboração de termo referência de Educação Ambiental FEHIDRO. São Paulo: SMA/CEA, 2011. Disponível em: <http://www.sigrh.sp.gov.br/public/uploads/documents/7341/roteiro-paraelaboracao-de-projetos-fehidro-caap-pagina-cea.pdf>. Acesso em: $08 \mathrm{dez}$. 2016.

SILVA, M.J.P. Onze passos do planejamento estratégico participativo. In: BROSE, M. (org) Metodologia participativa: uma introdução a 29 instrumentos. 2. ed., Porto Alegre: Tomo, 2010, p. 163-180.

SPINK, P. Inovação na perspectiva dos inovadores: a experiência do programa Gestão Pública e Cidadania. Cadernos EBAPE.BR, v. 1, n. 2, dez. 2003. Disponível em: $<$ http://www.scielo.br/scielo.php?script=sci arttext\&pid=S167939512003000200002>. Acesso em: 30/06/2014.

TORO, J.B.; WERNECK, N.M. Mobilização social: um modo de construir a democracia e a participação. Fundación Bogotá, 1996.

TRISTAO, V.T.V.; TRISTAO, J.A.M. A contribuição das ONGS para a Educação Ambiental: uma avaliação da percepção dos Stakeholders. Ambient Soc, São Paulo, v. 19, n. 3, p. 47-66, set. 2016. Disponível em: $<$ http://www.scielo.br/scielo.php?script=sci arttext\&pid=S1414-

753X2016000300047\& Ing=pt\&nrm=iso>. Acesso em: 03 nov. 2016

VASCONCELLOS, H.S.R. et al. Espaços educativos impulsionadores da Educação Ambiental. Cad CEDES, Campinas, v. 29, n. 77, p. 29-47, abr. de $2009 . \quad$ Disponível $<$ http://www.scielo.br/scielo.php?script=sci arttext\&pid=S0101$\underline{32622009000100003 \& \operatorname{lng}=e n \& n r m=i s o}>$. Acesso em: 12 maio 2015. 